\title{
Pengembangan Model Bisnis pada Lokawisata Baturaden Menggunakan Business Model Canvas
}

\author{
Business Model Analysis of Lokawisata Baturaden with the Business Model Canvas \\ Ratih Mukti Azhar1 ${ }^{*}$, Ono Suparno ${ }^{2}$, dan Setiadi Djohar ${ }^{3}$ \\ ${ }^{1 *}$ Sekolah Bisnis, Institut Pertanian Bogor \\ Jl. Raya Pajajaran-Bogor 16151 \\ ${ }^{2}$ Departemen Teknologi Industri Pertanian, Fakultas Teknologi Pertanian, IPB \\ Kampus IPB Dramaga PO. Box 220 Bogor 16002 \\ ${ }^{3}$ Sekolah Tinggi Manajemen PPM \\ Jl. Menteng Raya 9-19, Jakarta 10340
}

\begin{abstract}
ABSTRAK
Perkembangan sektor pariwisata di era globalisasi saat ini menuntut masing-masing pelaku usaha di sektor ini untuk terus mengembangkan bisnisnya, termasuk Lokawisata Baturaden yang merupakan salah satu tempat wisata alam di Jawa Tengah. Untuk itu dibutuhkan rancangan model bisnis yang tepat, agar Lokawisata Baturaden dapat mengetahui bagaimana menjalankan kegiatan pengelolaannya secara efektif dan efisien. Tujuan penelitian ini merancang model bisnis di masa depan sebagai langkah pengembangan Lokawisata Baturaden selanjutnya. Jenis penelitian adalah kualitatif deskriptif dengan metode pendekatan model bisnis kanvas (BMC) yang dilengkapi SWOT dan blue ocean strategy. Hasil penelitian menunjukan penciptaan proposisi nilai baru pada perancangan model bisnis dimasa depan berupa program hiburan eduwisata untuk anak dan keluarga di Lokawisata Baturaden memengaruhi setiap unsur bisnis model kanvas, yaitu terjadi penambahan dalam hal sumber daya utama yang dimiliki, aktivitas kunci yang dilakukan, mitra kerjasama, dan aliran pendapatan yang masuk. Struktur biaya yang dikeluarkan terjadi penambahan serta pengurangan biaya, dalam hal aktivitas promosi. Pada costumer segment, fokus utamanya adalah keluarga, anak-anak, dan pelajar.
\end{abstract}

Kata kunci: bisnis model kanvas, lokawisata, pariwisata, wisata alam

\begin{abstract}
The development of tourism sector in this era of globalization requires each business actor in this sector to continue development business including Lokawisata Baturaden which is one of the natural tourist attractions located in Central Java. Therefore, it is necessary to design the right business model so that Lokawisata Baturaden can understand how to run management activities effectively and efficiently. The objective of this study was to design a future business model of Lokawisata Baturaden as a developed tourism recreation. The analytical method utilized in the study was business model canvas (BMC) with SWOT and blue ocean strategy. The results showed that created of new value proposition for future business model design in the form of educational entertainment programs for children and families in Lokawisata Baturaden affected every element of the business model canvas such as the addition in terms of key resources owned, key activities undertaken, cooperation partners, and income streams who signed in. The cost structure incurred addition and reduction of costs in terms of promotional activities. Costumer segment, the main focus is family, children, and students.
\end{abstract}

Key words: business model canvas, lokawisata, nature tourism, tourism

\footnotetext{
*) Korespondensi:

Jl. Raya Pajajaran-Bogor 16151; email: ratihazhar_agribisnis@yahoo.co.id
} 


\section{PENDAHULUAN}

Sektor pariwisata merupakan salah satu industri pendorong dan penggerak perekonomian dunia. Saat ini, pariwisata telah mengalami ekspansi dan diversifikasi berkelanjutan dan menjadi salah satu sektor yang terbesar, serta tercepat pertumbuhannya di dunia. Kondisi kepariwisataan Indonesia pada tahun 2015 menurut Kementerian Pariwisata adalah baik secara kondisi makro maupun mikro menunjukan perkembangan dan peningkataan kontribusinya terhadap produk domestik bruto (PDB) nasional. Secara makro, terjadi peningkatan nyata terhadap PDB nasional 4,23\% atau senilai Rp461,36 triliun, dengan peningkatan devisa yang dihasilkan mencapai US\$ 11,9 milyar dan tenaga kerja pariwisata 12,16 juta orang. Pada kondisi mikro, terjadi peningkatan jumlah wisatawan mancanegara (wisman) 10,4 juta wisman dan wisatawan nusantara (wisnus) 255,20 juta perjalanan. Di sisi lain, salah satu indikator penting, yaitu aspek daya saing kepariwisataan, berdasar penilaian WEF (World Economic Forum), posisi Indonesia meningkat nyata dari ranking 70 dunia menjadi ranking 50 di tahun 2015. Pertumbuhan pariwisata Indonesia yang melebihi rataan dunia di tahun 2015 sebesar 10,63\% memberikan kepercayaan diri Kementerian Pariwisata untuk meningkatkan target kunjungan wisman pada tahun 2016 dari 10 juta menjadi 12 juta.

Peningkatan pertumbuhan pariwisata menjadikan sektor ini sebagai kunci dalam pendapatan ekspor, penciptaan lapangan kerja, pengembangan usaha dan infrastruktur, serta nilai strategiknya dapat menjadi sektor andalan bagi pembangunan nasional di masa depan, sehingga Pemerintah memberikan perhatian lebih besar terhadap sektor ini baik dalam hal kebijakan anggaran maupun dukungan sektoral lintas kementerian dan lembaga untuk mendukung pembangunan kepariwisataan nasional. Hal tersebut tercermin dari ketentuan pasal 35 Undang-Undang Nomor 10 Tahun 2009 tentang Kepariwisataan. Dalam rangka peningkatan penyelenggaraan kepariwisataan, maka pada tanggal 3 Juli 2014 telah ditetapkan Peraturan Presiden Republik Indonesia Nomor 64 Tahun 2014 tentang Koordinasi Strategik Lintas Sektor Penyelenggaraan Kepariwisataan. Peraturan Presiden tersebut mengatur tentang Koordinasi Strategis Lintas Sektor pada tataran kebijakan, program dan kegiatan kepariwisataan.
Pembangunan kepariwisataan dilaksanakan di daerah, sehingga koordinasi dan kolaborasi pengembangan destinasi dan pemasaran wisata harus didorong pada tingkat daerah dengan menjunjung tinggi prinsip pembangunan berkelanjutan dan berkeadilan. Pemerintah melakukan Koordinasi Strategis Lintas Sektor pada tataran kebijakan, program, dan kegiatan dalam rangka meningkatkan penyelenggaraan kepariwisataan sebagaimana diatur dalam Peraturan Presiden RI Nomor 64 Tahun 2014 tentang Koordinasi Strategis Lintas Sektor Penyelenggaraan Kepariwisataan (Kemenpar, 2015).

Kabupaten Banyumas merupakan salah satu kabupaten di Provinsi Jawa Tengah yang memiliki daya tarik wisata yang begitu bervariasi. Salah satu destinasi wisata andalan yang turut menjadi sumber pendapatan asli daerah (PAD) di sektor pariwisata adalah kawasan wisata alam Baturraden yang sudah dikenal baik oleh wisatawan lokal maupun mancanegara. Kawasan Baturaden berada di sebelah selatan kaki Gunung Slamet pada ketinggian sekitar $640 \mathrm{~m}$ di atas permukaan laut $(\mathrm{dpl})$, dengan suhu udara $18^{\circ}$ $25^{\circ} \mathrm{C}$. Kawasan wisata Baturaden memiliki beberapa destinasi wisata, salah satunya adalah Lokawisata Baturaden.

Lokawisata Baturaden merupakan salah satu destinasi wisata yang dikelola oleh Dinas Pariwisata Kabupeten Banyumas yang paling banyak dikunjungi wisatawan dibandingkan destinasi wisata lainnya yang terdapat di Kawasan Wisata Baturaden dikarenakan obyek wisata ini memiliki atraksi cukup lengkap seperti air terjun, taman botani, dan arena mainan anak dan keluarga. Selain itu, di dalam lokasi ini juga terdapat arena permainan air.

Pada tahun 2015 terjadi peningkatan 61 persen dari tahun sebelumnya dan mengindikasikan jika Lokawisata Baturaden saat ini mulai dikelola dengan lebih baik. Hal tersebut juga dibuktikan dari pencapaian Lokawisata Baturaden yang pada tahun 2015 meraih juara pertama Penghargaan Kepariwisataan Tingkat Provinsi Jawa Tengah dalam kategori daya tarik wisata yang dikelola pemerintah mengalahkan dua nominasi lainnya yaitu Taman Kyai Langgeng, Kota Magelang dan Kawasan Wisata Dataran Tinggi Dieng, Banjarnegara.

Pencapaian pada tahun 2015 ini menunjukkan bahwa Lokawisata Baturaden seharusnya mampu menjadi ikon wisata alam yang banyak dikunjungi oleh wisatawan dalam negeri maupun 
mancanegara. Tetapi pada kenyataannya wisatawan yang berkunjung ke Lokawisata Baturaden masih sebagian besar merupakan wisatawan lokal, sedangkan untuk wisatawan mancanegara masih terbilang sedikit persentasenya, yaitu kurang dari lima persen setiap tahunnya.

Hal tersebut menandakan bahwa pengelolaan Lokawisata Baturaden masih belum menghasilkan kinerja optimal, dimana dalam pengembangan pasar masih perlu dikaji ulang mengenai strategi yang tepat dalam mempromosikan wisata ini. Selain itu potensi sumberdaya wisata yang ada masih belum optimal dalam pemanfaatannya menjadikan Lokawisata Baturaden perlu untuk merumuskan model bisnis yang sesuai dengan kondisi yang ada, agar tetap menjadi wisata andalan Banyumas dengan persentase penyum-bang pendapatan terbesar Kabupaten Banyumas serta berkelanjutan. Salah satu konsep bisnis yang digunakan untuk merumuskan strategi pengembangan usaha adalah Business Model Canvas (BMC). Tujuan penelitian ini adalah merancang ide perencanaan model bisnis Lokawisata Baturaden di masa depan dengan melihat kondisi BMC Lokawisata Baturaden saat ini dan SWOT.

\section{METODE PENELITIAN}

Penelitian dilakukan di Lokawisata Baturaden yang berada di desa Ketenger Kabupaten Banyumas, Jawa Tengah. Penelitian ini dilakukan pada bulan Desember-Mei 2017. Penelitian ini dilakukan dengan menggunakan metode deskriptif kualitatif melalui pendekatan studi kasus.

Data yang digunakan penelitian ini adalah data primer dan data sekunder. Data primer diperoleh dari hasil wawancara dengan informan penelitian. Enam informan yang digunakan dalam penelitian berasal dari internal perusahaan dengan jabatan Kepala Dinas Pemuda dan Olahraga, Kepala Bidang Pariwisata dan Kepala Unit Pelaksana Teknis (UPT) Lokawisata Baturaden dan dari bagian eksternalnya berasal dari pengunjung Lokawisata Baturaden, pemilik usaha di tempat wisata tersebut dan masyarakat sekitar. Data sekunder merupakan data yang telah dikumpulkan pihak lain, yaitu berupa dokumen, buku-buku literatur, dan internet. Teknik pengumpulan data yang digunakan dalam penelitian ini dilakukan melalui: (1) Wawancara dan kuesioner, teknik wawancara dilakukan dalam bentuk diskusi dan komunikasi dua arah dengan menyusun daftar pertanyaan yang telah dipersiapkan sebelumnya; (2) Observasi melalui pengamatan dan pencatatan terhadap instansi yang terkait dalam penelitian dan objek (sasaran) yang sedang diteliti; (3) FGD terhadap internal manajemen dan beberapa pihak di luar tim manajemen inti yang memiliki kapasitas pengetahuan terkait bidang stategi pengembangan dengan tujuan memperkaya pandangan mengenai model bisnis di masa depan; (4) Dokumentasi yang didapatkan melalui sejumlah data dan informasi di lapangan berupa dokumen administratif yang diperoleh melalui wawancara, observasi dan data sekunder.

Perancangan pengembangan model bisnis pada Lokawisata Baturaden dilakukan melalui serangkaian analisis yang diawali dengan analisis deskriptif yang menganalisis kondisi saat ini. Identifikasi terhadap kesembilan unsur BMC yaitu Customer Segments (CS), Value Propositions (VP), Channels (CH), Customer Relationships (CR), Revenue Streams (RS), Key Resources (KR), Key Activities (KA), Key Partnerships (KP), dan Cost Structures (CS) diperlukan untuk mengetahui sasaran yang ingin dicapai organisasi menurut tujuan yang akan dicapai. Selanjutnya, setiap unsur dinilai secara detail dengan analisis SWOT. Analisis ini menggambarkan strategi bisnis yang dilahirkan dengan kolaborasi faktor internal (kekuatan dan kelemahan) dan faktor eksternal (peluang dan ancaman). Identifikasi kesembilan unsur BMC dan SWOT merupakan dasar dalam perancangan prototipe model bisnis di masa depan. Perumusan prototipe model bisnis baru ini dilakukan dengan Blue Ocean Strategy dengan perangkat analisis kerangka kerja empat langkah dan skema hapuskan-kurangi-tingkatkan-ciptakan.

\section{HASIL DAN PEMBAHASAN}

\section{Potret Model Bisnis saat ini}

Kondisi BMC pada Lokawisata Baturaden ditentukan berdasarkan hasil wawancara dengan narasumber yang kemudian menghasilkan informasi akurat mengenai sembilan elemen BMC pada Lokawisata Baturaden. Proses identifikasi kesembilan unsur tersebut melibatkan pihak internal dari pengelolaan Lokawisata Baturaden yang terdiri dari Kepala Dinas Din-porabudpar Kabupaten Banyumas, Kepala Bidang Pariwisata dan kepala UPT Lokawisata Baturaden beserta anggotanya. Responden tersebut dinilai memiliki kapasitas untuk memberikan informasi relevan 
terkait dengan data yang dibutuhkan untuk mengidentifikasi sembilan unsur BMC sebagai potret kondisi model bisnis Lokawisata Baturaden saat ini. Identifikasi kesembilan unsur BMC pada Lokawisata Baturaden saat ini adalah pada sisi customer segment, pengunjung merupakan wisatawan domestik dan wisatawan asing. VP yang ditawarkan adalah wisata alam yang berbasis lingkungan, tiket yang murah dan aksesabilitas yang mudah. CR yang berlangsung saat ini adalah pelayanan keramahtamahan dan melalui komunitas kepada pengunjung dan saluran distribusinya langsung mengandalkan word of mouth (WOM) dan tidak langsung dengan pengunjung melalui kegiatan promosi seperti iklan, pameran maupun komunitas. Pendapatan yang diterima dari
Anggaran Pendapatan dan Belanja Daerah (APBD), biaya sewa, tiket masuk dan tarif parkir. Key resource pada tempat wisata ini adalah aset fisik, yaitu keindahan alam pegunungan, sumber daya manusia dan branding. Key activities yang ada adalah kegiatan pelayanan dan kegiatan pemeliharaan atau pemantauan kondisi alam dan infrastrukturnya. Key partnership yang dilakukan saat ini adalah dengan masyarakat sekitar, investor, pengusaha hotel maupun travel dalam kegiatan promosi dan instansi terkait seperti dinas pekerjaan umum dalam hal perbaikan atau kegiatan operasional wisata. Struktur biaya utama adalah biaya untuk gaji tetap yakni bagi karyawan, biaya pemeliharaan, dan biaya promosi.

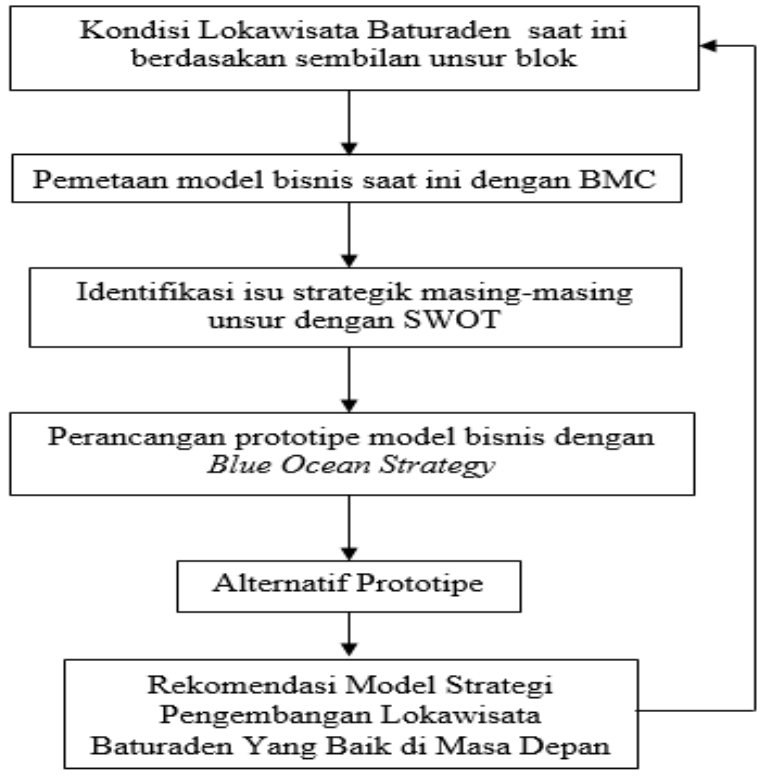

Gambar 1. Kerangka pemikiran konseptual

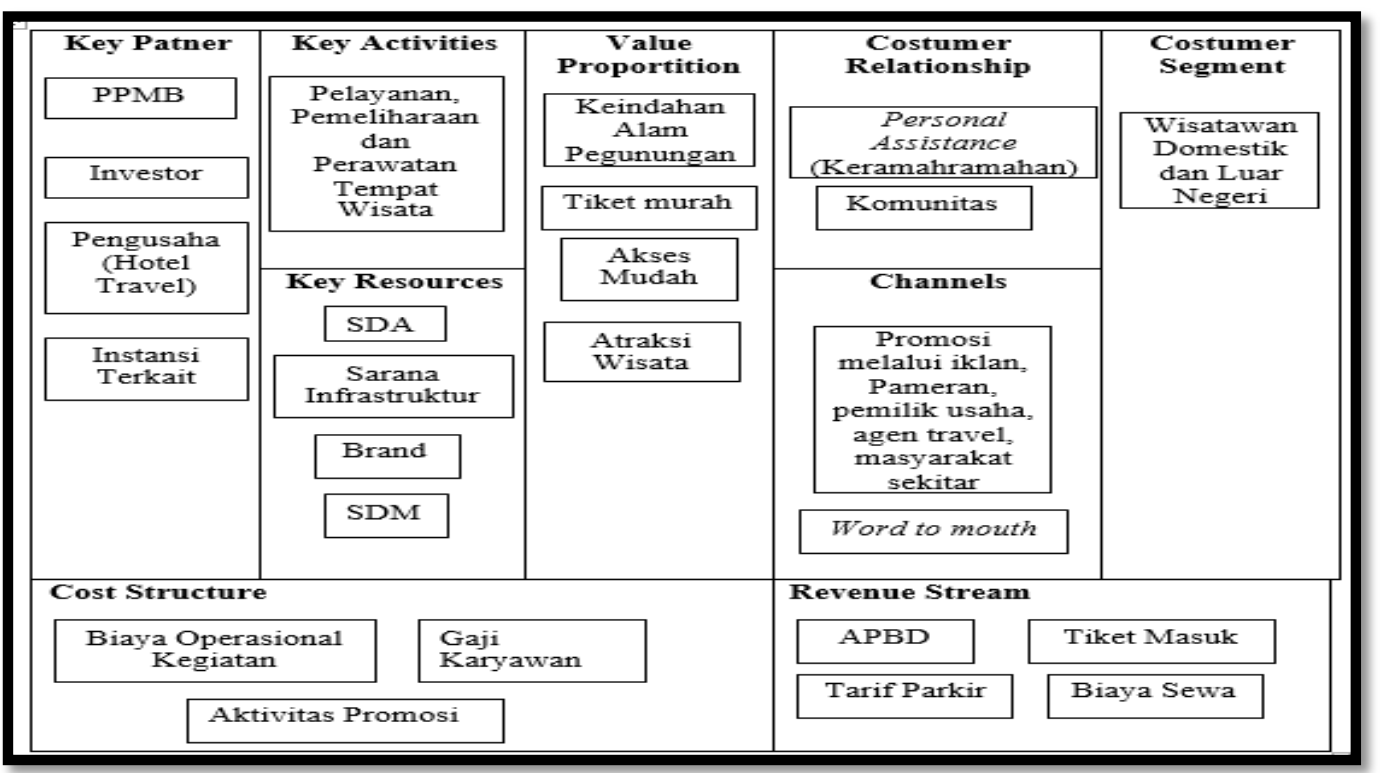

Gambar 2. Identifikasi model bisnis kanvas Lokawisata Baturaden saat ini 
Identifikasi SWOT pada setiap BMC Model Bisnis Lokawisata Baturaden

Selanjutnya dilakukan identifikasi kondisi setiap unsur model bisnis kanvas saat ini dengan pemetaan terhadap kekuatan, kelemahan, ancaman dan peluang dari setiap unsur BMC Lokawisata Baturaden. Hasil identifikasi SWOT tiap unsur BMC digunakan untuk perancangan prototipe model bisnis baru yang akan dijalankan Lokawisata Baturaden di masa depan. Berdasarkan hasil wawancara, pengisian kuesioner dan observasi, maka hasil identifikasi SWOT kesembilan unsur BMC Lokawisata Baturaden ditunjukan pada Tabel 1.

\section{Perancangan Model Bisnis Melalui Blue Ocean Strategy}

Dalam mendesain model bisnis, baik menyempurnakan maupun membuat prototipe model bisnis lain, membangun ide merupakan bagian paling mendasar dan terpenting yang harus dilakukan perusahaan. Ide untuk inovasi model bisnis dapat diperoleh dari mana saja dan kesembilan building blocks dapat menjadi titik awal memulai inovasi. Inovasi model bisnis transformatif memengaruhi lebih dari satu building block. Terdapat empat pusat dari inovasi model bisnis, diantaranya resources-driven, offerdriven, customer-driven dan finance-driven. Masingmasing pusat inovasi ini posisinya sebagai titik awal bagi perubahan besar model bisnis dan memberikan dampak kuat bagi kedelapan building block lainnya. Selain itu, perubahanperubahan yang terjadi sering berasal dari areaarea yang diidentifikasi melalui analisis SWOT dengan menginvestigasi kekuatan, kelemahan, peluang, dan ancaman dalam suatu model bisnis.

Pada penelitian ini, ditawarkan ide perancangan model bisnis berbasis blue ocean strategy. Ide perencanaan model bisnis berbasis blue ocean strategy ini terpacu dari beberapa titik pusat inovasi, diantaranya pada titik aktivitas kunci (key activities) dan titik penawaran (value proportition). Pembentukan tim hiburan (entertainment team) menjadi awal perencanaan ide dari model bisnis ini dimana fungsinya menangani berbagai program-program hiburan dari masingmasing segmen konsumen. Berdasarkan kondisi

Tabel 1. Hasil analisis SWOT BMC Lokawisata Baturaden

\begin{tabular}{|c|c|c|c|c|c|}
\hline No & Aspek & Kekuatan & Kelemahan & Peluang & Ancaman \\
\hline 1 & $\begin{array}{l}\text { Costumer } \\
\text { Segment }\end{array}$ & $\begin{array}{l}\text { Segmen pengunjung } \\
\text { yang beraneka ragam }\end{array}$ & $\begin{array}{l}\text { Pengelola melayani } \\
\text { dan menganggap } \\
\text { sama setiap segmen }\end{array}$ & $\begin{array}{l}\text { Pertumbuhan } \\
\text { wisatawan skala } \\
\text { nasional, kebijakan } \\
\text { pemerintah }\end{array}$ & $\begin{array}{l}\text { Pesaing dengan } \\
\text { segmen konsu- } \\
\text { men yang sama }\end{array}$ \\
\hline 2 & $\begin{array}{l}\text { Value } \\
\text { Proportition }\end{array}$ & $\begin{array}{l}\text { Potensi alam Baturaden, } \\
\text { tiket murah, } \\
\text { aksesabilitas mudah }\end{array}$ & $\begin{array}{l}\text { Sarana prasarana } \\
\text { belum memadai }\end{array}$ & $\begin{array}{l}\text { Potensi wisata alam } \\
\text { dan budaya belum } \\
\text { dioptimalkan }\end{array}$ & $\begin{array}{l}\text { Pesaing yang } \\
\text { semakin } \\
\text { kompetitif }\end{array}$ \\
\hline 3 & Channels & Distribusi langsung kuat & $\begin{array}{l}\text { Promosi via sosial } \\
\text { media masih belum } \\
\text { dikembangkan }\end{array}$ & $\begin{array}{l}\text { Kemajuan teknologi } \\
\text { informasi }\end{array}$ & $\begin{array}{l}\text { Pesaing semakin } \\
\text { gencar melakukan } \\
\text { promosi }\end{array}$ \\
\hline 4 & $\begin{array}{l}\text { Costumer } \\
\text { Relationship }\end{array}$ & $\begin{array}{l}\text { Hubungan baik dengan } \\
\text { masyarakat sekitar }\end{array}$ & $\begin{array}{l}\text { Pengelola cederung } \\
\text { pasif dalam } \\
\text { menarik konsumen }\end{array}$ & $\begin{array}{l}\text { Pemanfaatan } \\
\text { teknologi media } \\
\text { sosial }\end{array}$ & \\
\hline 5 & $\begin{array}{l}\text { Revenue } \\
\text { Stream }\end{array}$ & $\begin{array}{l}\text { Sumber pendapatan } \\
\text { bervariasi dan tetap }\end{array}$ & Birokrasi & $\begin{array}{l}\text { Terbukanya sumber } \\
\text { pemasukan baru }\end{array}$ & $\begin{array}{l}\text { Keterbatasan dana } \\
\text { APBD }\end{array}$ \\
\hline 6 & $\begin{array}{l}\text { Key } \\
\text { Resources }\end{array}$ & $\begin{array}{l}\text { Keunikan potensi SDA } \\
\text { dan Branding kuat }\end{array}$ & $\begin{array}{l}\text { SDM secara kualitas } \\
\text { dan kuantitas masih } \\
\text { kurang }\end{array}$ & $\begin{array}{l}\text { Penggunaan } \\
\text { teknologi }\end{array}$ & $\begin{array}{l}\text { Ancaman bencana } \\
\text { alam gunung } \\
\text { meletus }\end{array}$ \\
\hline 7 & Key Activities & $\begin{array}{l}\text { Pelayanan, } \\
\text { pemeliharaan dan } \\
\text { perawatan sesuai } \\
\text { kewajiban } \\
\end{array}$ & $\begin{array}{l}\text { APBD tidak banyak } \\
\text { sehingga proses } \\
\text { pemeliharaan masih } \\
\text { sebagian }\end{array}$ & & \\
\hline 8 & $\begin{array}{l}\text { Key } \\
\text { Partnerships }\end{array}$ & $\begin{array}{l}\text { Kemitraan dengan } \\
\text { berbagai pihak dan } \\
\text { masyarakat sekitar }\end{array}$ & $\begin{array}{l}\text { Tumpang tindih } \\
\text { kepentingan banyak } \\
\text { pihak }\end{array}$ & $\begin{array}{l}\text { Terbukanya peluang } \\
\text { kerjasama dengan } \\
\text { banyak pihak }\end{array}$ & \\
\hline 9 & $\begin{array}{l}\text { Cost } \\
\text { Structure }\end{array}$ & $\begin{array}{l}\text { Dana yang masuk dapat } \\
\text { terpenuhi }\end{array}$ & $\begin{array}{l}\text { Biaya operasional } \\
\text { tinggi dan pengelo- } \\
\text { laan dana masih } \\
\text { belum efisien }\end{array}$ & $\begin{array}{l}\text { Menekan biaya } \\
\text { dengan kegiatan } \\
\text { promosi via internet }\end{array}$ & $\begin{array}{l}\text { Kondisi politik } \\
\text { ekonomi tidak } \\
\text { stabil }\end{array}$ \\
\hline
\end{tabular}


saat ini dapat diketahui bahwa Lokawisata Baturaden tidak memiliki banyak event dan masih mengandalkan wahana-wahana rekreasi sehingga peran dari entertainment team ini mampu memberikan hal baru di Lokawisata Baturaden. Dalam perencanaan model bisnis ini, entertaiment team menangani dua program, yaitu The Show Timedan Mini Club/Kids Arena. The Show Time merupakan program hiburan berupa berbagai festival musik maupun budaya, baik kontemporer maupun tradisional ataupun penggabungan keduanya. Mini Club merupakan program yang ditunjukan oleh keluarga dan anak sekolah berupa paket dengan konsep wisata edukatif. Dalam menjalankan perencanaan model bisnis ini, Lokawisata Baturaden menjalin kemitraan dengan PPMB yang bertanggung jawab dalam menangani The Show Time. Untuk program Mini Club dilakukan perekrutan individu menurut rencana program yang diinginkan. Peningkatan peran
PPMB sebagai mitra dari Lokawisata Baturaden ini merupakan titik pusat inovasi yang terpacu oleh aktivitas kunci (key activities), sedangkan program Mini Club ditawarkan pada perencanaan model bisnis yang merupakan titik pusat inovasi terpacu oleh penawaran (value proportition). Kedua titik inovasi ini memengaruhi unsur-unsur blok bangunan lainnya.

Pada perancangan prototipe model bisnis yang dikombinasikan dengan prinsip blue ocean strategy mengangkat empat pertanyaan utama, yaitu apa yang bisa diciptakan (create), dihilangkan (eliminate), ditingkatkan (rise) dan dikurangi (reduce) yang mengacu pada kondisi saat ini dan di masa mendatang. Dengan demikian perancangan model bisnis ini diharapkan tidak hanya melakukan perbaikan tetapi juga memunculkan inovasi baru diluar kompetensi inti yang dimiliki Lokawisata Baturaden.

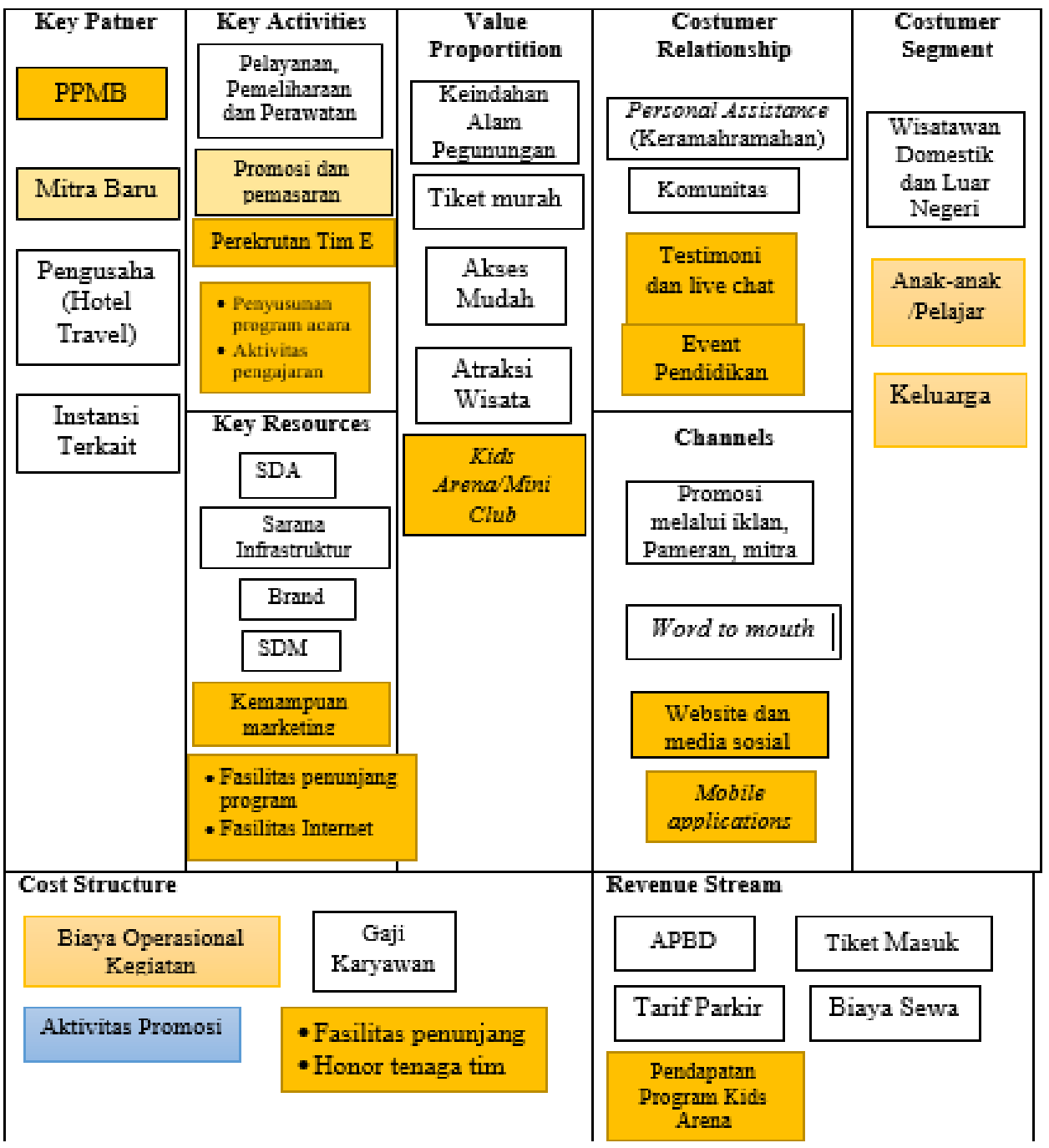

Keterangan :

= ditingkatkan; $\square$ =dikurangi; $\square$ =diciptakan; $\square$ =dieliminasi

Gambar 3. Prototipe bisnis model kanvas Lokawisata Baturaden di masa depan 


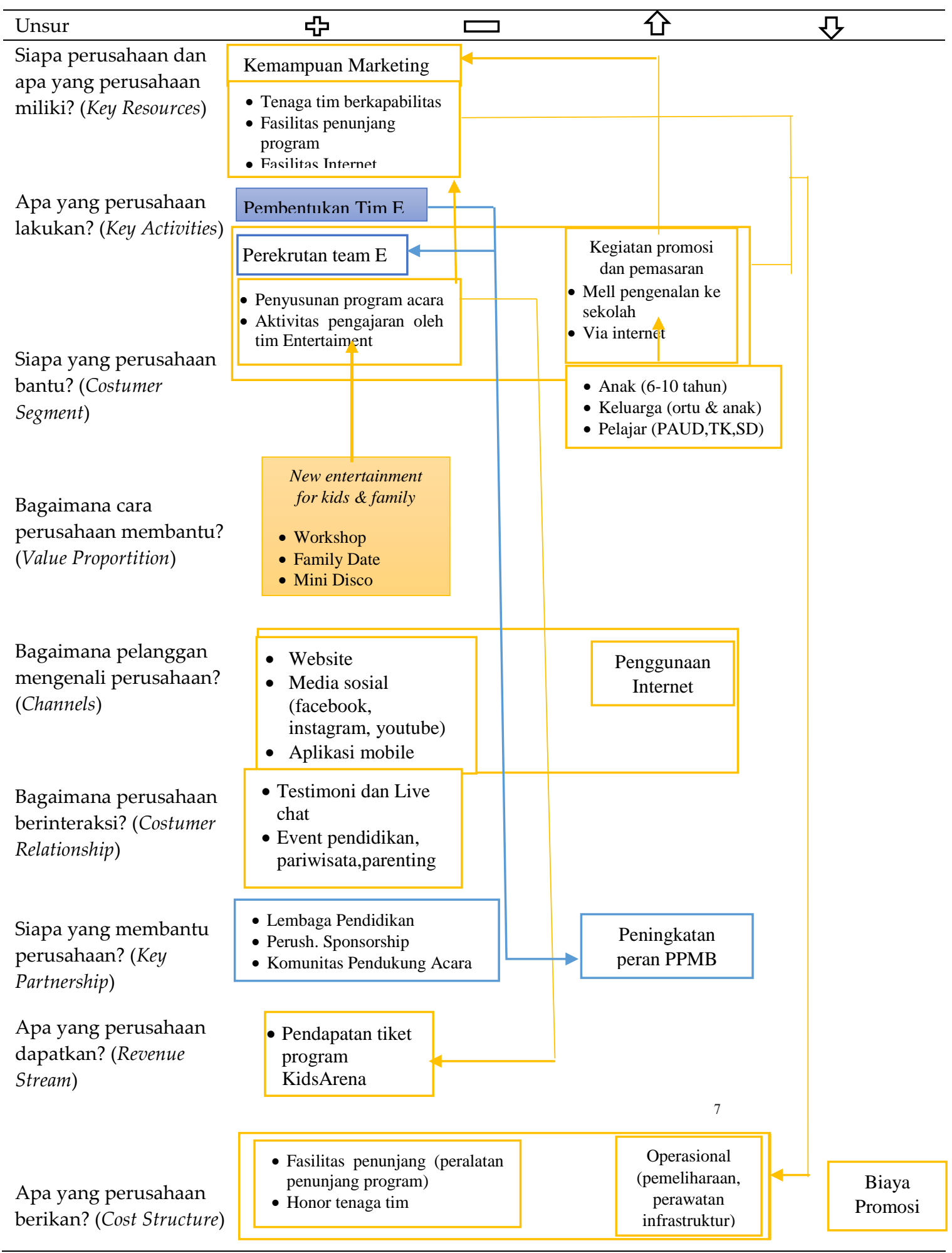

Gambar 4. Ide kerangka empat tindakan prototipe model bisnis Lokawisata Baturaden

\section{KESIMPULAN}

Hasil penelitian menunjukan bahwa ide perencanaan model bisnis berbasis blue ocean strategy dapat dijalankan oleh Lokawisata Baturaden untuk mengembangkan bisnis wisatanya di masa depan. Ide perencanaan ini terpacu dari beberapa titik pusat inovasi, yaitu titik aktivitas kunci (key activities) dimana Lokawisata Baturaden melakukan pembentukan tim entertainment yang bertujuan untuk meningkatkan peran PPMB dalam berbagai event yang diselenggarakan dan titik penawaran berupa program hiburan baru yaitu eduwisata. 


\section{DAFTAR PUSTAKA}

Bagindo, M. 2015. Analisis Model Bisnis Ekowisata di Taman Nasional Laut Bunaken dengan Pendekatan Business Model Canvas [tesis]. Bogor (ID): Institut Pertanian Bogor.

Chandra, U. 2015. Baturaden dan Samiran Raih Penghargaan Pariwisata. Semarang [Internet]. [diunduh pada 26 Agustus 2016]. Tersedia pada: http://berita.suaramerdeka.com/smcetak/baturraden-dansamiran-raih-penghargaan-pariwisata2015/

[DINPARBMS] Dinas Pariwisata Kabupaten Banyumas. 2015. Statistik Kunjungan dan Pendapatan Wisata Kabupaten Banyumas. Purwokerto: Dinpar.

Iskandariansyah, M. 2013. Analisis Model Bisnis Ekowisata di Pulau Pramuka Kepulauan Seribu dengan endekatan Business Model Canvas [Tesis]. Bogor (ID): Institut pertanian Bogor.
[KEMENPAR] Kementerian Pariwisata Republik Indonesia. 2015. Laporan Akuntabilitas Kinerja Kementerian Pariwisata Tahun 2015 (ID). (diunduh 23 Juli 2016). Tersedia pada: http://kemenpar.go.id.

Kim, W.C., R. Mauborgne. 2005. Blue Ocean Strategy: How to Create Uncontested Market Space and Make Competition Irrelevant. Boston (US): Harvard Bussiness School Pr.

Osterwalder, A., dan Y. Pigneur. 2010. Business Model Generation (terjemahan). Jakarta (ID): PT Elex Media Computido.

Tim PPM Manajemen. 2012. Busines Model Canvas: Penerapan di Indonesia. Jakarta (ID): Penerbit PPM.

Whelan. 1991. Nature Tourism: Managing the Environment. Washington (US): Island Press.

Wiska, F. 2016. Bussiness Model Canvas Sekolah Perternakan Rakyat di Kecamatan Kedungadem Kabupaten Bojonegoro. [tesis]. Bogor (ID): Institut Pertanian Bogor. 